\title{
The Innovation of Education in the Era of Artificial Intelligence $^{+}$
}

\section{Juan Shen}

School of Marxism, Wuhan University of Technology, Wuhan, Hubei 430070, China; murphy_shen@outlook.com; Tel.: +86-1592-643-4836

+ The Fourth International Conference on Philosophy of Information, Berkeley, CA, USA, 2-6 June 2019.

Published: 5 June 2020

\begin{abstract}
With the development of artificial intelligence, the field of education is facing unprecedented challenges and great opportunities-how education will change and how to innovate and develop. Through studying the development of artificial intelligence, analyze the artificial intelligence influence in education, especially the revolutionary change in schools, teachers, and students, in order to have a comprehensive understanding of artificial intelligence, on this basis, explore the path of education innovation, and cultivate new talents to meet the requirements of artificial intelligence development.
\end{abstract}

Keywords: artificial intelligence; education; learning; innovation

\section{Introduction}

From 2016, artificial intelligence began to heat up, and it became a hot topic of discussion from all walks of life. In July 2017, the state council issued the development plan for the new generation of artificial intelligence, which for the first time, elevated the development of artificial intelligence to a national strategy and set out the three-step strategic goal by 2030. It also clearly pointed out that the rapid development of artificial intelligence will profoundly change the life of human society and the world. Therefore, what impact will AI have on education? What opportunities and challenges will it bring to higher education in the future? How can it promote the reform of college students' traditional learning mode? These become the problems that educators need to study urgently.

\section{The Development of Artificial Intelligence}

The definition of Artificial Intelligence (AI) is an evolving process, with its implications evolving as the field progresses.

As early as 1950, Alan Turing, the father of artificial intelligence, proposed the Turing test theory as well as various concepts such as machine learning, genetic algorithm and reinforcement learning. At the Dartmouth conference in 1956, John McCarthy, an American computer scientist, and his colleagues first introduced the concept of artificial intelligence by discussing the unsolved problems in computer science at the time. Artificial intelligence then had a brief development. However, as new technologies and industrial chains were not broken through and new products were not invented, government support and business investment were greatly reduced, and artificial intelligence research and development entered an ebb. Into the 21st century, because of the historical process of a new round of technological change and industrial revolution, artificial intelligence is playing a leading role. 


\section{The Impact of Artificial Intelligence on Traditional Education}

In the era of artificial intelligence, the function of education is no longer "to preach, to receive, to solve", but to reshape the human brain itself. The challenge of artificial intelligence to education will be a comprehensive and three-dimensional continuous process.

\subsection{The Impact of Artificial Intelligence on Schools-Schools Will No Longer Exist}

The modern school system is to adapt to the needs of a large number of industrial workers in the industrial age, in accordance with the requirements of the standardization of mass cultivation of talent needed in that era. In the era of artificial intelligence, a large number of jobs and industries will disappear, and artificial intelligence will completely replace them.

Schools may not exist in the future, but a new kind of learning center will be born. Students can choose courses to study in different learning centers. In the future, the learning center will be a learning community. All courses will be publicly selected and credits will be recognized.

\subsection{The Impact of Artificial Intelligence on Teachers-Teachers Will Be Replaced}

In artificial intelligence era, a lot of knowledge of the professor has been outsourced to the machine, and even a lot of things artificial intelligence can help you learn-the machine will help you learn.

When this repetitive teaching is carried out by artificial intelligence, what should teachers do? The teaching of artificial intelligence is more accurate, faster and more efficient than a human being. Then, what is the use of teachers?

\subsection{The Impact of Artificial Intelligence on Students-Students Do Not Learn}

Artificial intelligence is cleverer than the human, and their memory is stronger than the human's - their memory capacity is bigger than the human brain's - their reaction speed is faster than the human's, their efficiency is higher than the human's. A lot of memory knowledge does not need you to learn, as artificial intelligence helps you to learn; for operational things, artificial intelligence helps you to do them. As a student, what else do you need to learn? Is it necessary to learn? Are students who do not study still students?

\section{Opportunities for Educational Reform in the Era of Artificial Intelligence}

Artificial intelligence brings us not only the challenge of subversion, but also the opportunity of innovation.

\subsection{The Future Learning Center Makes Education Better}

In the learning center in the future, each student is to be a happy student, with autonomous learning, to let every student really enjoy the process of learning life and really enjoy education, to let every student find their potential and talent, to let every student find achievement in the process of learning, and become the best they can be. The future learning center makes education better, happier and more complete.

\subsection{Teachers Change from "Imparting Knowledge and Solving Doubts" to "Preachers"}

When the function of "imparting knowledge and solving doubts" is replaced, teachers will have more time and energy to help students develop their creativity; to focus on improving students' quality and emotional intelligence; to help students form correct values, establish a sound ideological system, and strive to make students become excellent talents with good personality and innovation ability in line with the requirements of the era of artificial intelligence. Teachers have also changed from the past teaching center status to a companion, mentor and learning partner, who can identify the emotions of students, thus helping students to build their mental health. 


\subsection{Improve Students' AI Literacy and Adapt to the Era of Artificial Intelligence}

Education in the era of artificial intelligence is mainly to cultivate students' AI literacy, correctly understand and use artificial intelligence, have systematic thinking ability, and be able to view the relationship between the human and machine dialectically; have the courage of continuous innovation, full of entrepreneurial spirit, and let creative thinking apply to study, life and work; have critical thinking and be capable of rational analysis, rather than subjection to artificial intelligence; with humanistic feelings, he has cultivated the ability of communication and cooperation in practice, and is full of sympathy, empathy and self-confidence.

\section{Conclusions}

Artificial intelligence in the education is a kind of intelligent education, and schools, teachers and students have to keep up with the pace of the times, reform educational modes, actively innovate the development path of education, and teachers' roles should be changed, to adapt the residents in the "artificial intelligence era".

\section{References}

1. Tencent Research Institute. Artificial Intelligence; Renmin University of China Press: Beijing, China, 2017; pp. 344-345. (in Chinese).

2. Li, W. The change of college students' learning mode in artificial intelligence era. China Adult Education. 2018, 21, 75-77.

3. Jaspers, K. What Is Education; Life, Reading, New Knowledge, Sanlian Bookstore: Beijing, China, 1991; Volume 4 .

4. Huang, R.; Zhang, J.; Hu, Y. Smart campus: the inevitable trend of digital campus development. Open Education. Res. 2012, 8, 12-17.

(C) 2020 by the authors. Licensee MDPI, Basel, Switzerland. This article is an open access article distributed under the terms and conditions of the Creative Commons Attribution (CC BY) license (http://creativecommons.org/licenses/by/4.0/). 